\title{
Encuentros, discusiones y desafíos en el quehacer antropológico contemporáneo
} (A propósito de la Primera Conferencia Nacional
de Migraciones y Refugio)

Silvia Zelaya ${ }^{1}$

\author{
1 Universidad de La Laguna. La Laguna, España \\ ORCID: 0000-0002-1107-3593 \\ Correo electrónico: szelayaa@ull.edu.es
}

Recibido:

noviembre de 2019

Aceptado:

abril de 2020

doi: 10.34096/runa.v41i1.8132

\section{Resumen}

Entre 2014 y 2016 acompañé las demandas de activistas por los derechos de los migrantes - personas de organizaciones religiosas, de organizaciones no gubernamentales, de movimientos de inmigrantes e investigadores- en las ciudades de Porto Alegre y San Pablo. A finales del mes de mayo de 2014 se celebró en esta ciudad la Primera Conferencia Nacional de Migraciones y Refugio. Este artículo retoma escenas de mi trabajo de campo relacionadas con la conferencia, para revelar algunas formas del quehacer antropológico en medio de prácticas institucionales. Entendiendo estas prácticas como tecnologías de control, argumento que existen dos modos de hacer y pensar políticas migratorias: la que encarna la conferencia nacional y la que encarnan los migrantes y refugiados que viven en el centro de San Pablo. Dos modos de lucha que presentan tensiones y desafíos distintos en el quehacer antropológico.

\section{Meetings, discussions and challenges in contemporary anthropological work. (On the First National Conference on Migration and Refuge)}

Between 2014 and 2016 I accompanied the demands of activists for the rights of migrants - people from religious organizations, non-governmental organizations, migrant movements and researchers- in the cities of Porto Alegre and San Pablo. At the end of May 2014, the First National Conference on Migration and Refuge was held in San Pablo. This article takes up scenes from my fieldwork in Brazil related to the Conference, to reveal some forms of anthropological work in the midst of institutional practices. Understanding these practices as control technologies, I argue that there are two ways of doing and thinking about migration policies: the one embodied by the National Conference and the one embodied by the migrants and refugees living in

\section{Palavras-chave}

Políticas migratorias; Prácticas institucionales; Tecnologías de control; Refugio; Quehacer antropológico

\section{Palabras clave}

Migration policies; Institutional practices; Control technologies; Refuge; Anthropological work 
downtown San Pablo. Two modes of struggle that present different tensions and challenges in anthropological work.

\section{Encontros, discussões e desafios no trabalho antropológico contemporâneo. (Sobre a Primeira Conferência Nacional de Migração e Refúgio)}

Palavras-chave

Políticas migratórias; Práticas institucionais; Tecnologias de controle; Refúgio; Trabalho
Entre os anos 2014 e 2016 acompanhei as demandas de ativistas pelos direitos dos migrantes -pessoas de congregações religiosas, de organizações não governamentais, de movimentos de imigrantes e pesquisadores- em Porto Alegre e San Pablo. No final de maio de 2014, foi realizada nessa cidade a Primeira Conferência Nacional sobre Migração e Refúgio. Este artigo retoma cenas do meu trabalho de campo no Brasil relacionado à Conferência, para revelar algumas formas de trabalho antropológico em meio às práticas institucionais. Entendendo essas práticas como tecnologias de controle, defendo que há duas formas de fazer e pensar as políticas migratórias: a encarnada pela Conferência Nacional e a encarnada pelos migrantes e refugiados que vivem no centro de San Pablo. Dois modos de luta que apresentam diferentes tensões e desafios no trabalho antropológico.

\section{El encuentro}

Cientos de personas llegadas de distintos lugares de Brasil esperaban ansiosas en el salón de actos de la Casa de Portugal, el inicio de la Primera Conferencia Nacional de Migraciones y Refugio (Comigrar). Era la mañana del 30 de mayo de 2014 y estaba por comenzar uno de los eventos más esperados por numerosos agentes mediadores del campo migratorio. Miembros de congregaciones religiosas, activistas de derechos humanos, académicos y migrantes recorrieron miles de kilómetros para participar en San Pablo de lo que fuera considerado por un importante sector del gobierno como un "momento histórico". La convocatoria para la celebración de esta conferencia nacional invitaba a crear una reflexión colectiva y contribuir en la elaboración de aportes para la construcción de una política nacional y de un plan nacional de migraciones y refugio. La Comigrar había sido convocada desde el ámbito nacional a finales del año 2013 y, desde entonces, importantes representantes del gobierno manifestaron un posicionamiento a favor de lo que llamaron "un cambio significativo en la orientación de las políticas migratorias".

La llegada de inmigrantes al territorio brasileño se había convertido en los meses previos a la conferencia en objeto recurrente de controversias y tensiones. En todos los eventos sobre migraciones en los que había participado hasta el momento se debatía sobre las condiciones de vida de los "recién llegados", y se exponían situaciones de extrema precariedad y de violaciones de derechos humanos. Para las personas que asistían a estos eventos era necesaria la sustitución del "Estatuto del Extranjero" (Ley 6.815 de 1980) por una nueva ley de migraciones. El pedido abogaba por una ley que no solo regulara la vida de los individuos de otras nacionalidades en Brasil, sino que determinara el tratamiento dado a los movimientos migratorios en el país. Muchas de las personas que participaban de estos encuentros creían que era 
necesario fortalecer una visión "contemporánea" de la cuestión migratoria, que no intentara "proteger al país de la amenaza externa", sino "integrar a los individuos regionalmente". Frente a la perspectiva de la Seguridad Nacional, encarnada en el Estatuto del Extranjero, la defensa de los derechos humanos de los migrantes se presentaba como una forma "distinta" de política migratoria.

Una parte de la literatura sobre políticas migratorias se ha centrado en analizar y revelar las nuevas formas de control de las migraciones y su funcionamiento. Así por ejemplo, tomando como foco de análisis la introducción del concepto de "migración ordenada" vinculada a la emergencia de un "nuevo régimen global de control", Eduardo Domenech (2013) ha contribuido al conocimiento del origen y fundamento de algunos cambios en las formas de pensar y ejercer el control de las migraciones internacionales en el escenario sudamericano más reciente. Otros trabajos, como los de Piscitelli (2008), Mansur Dias y Sprandel (2011), Magliano y Clavijo (2013), Piscitelli y Lowenkron (2015), han problematizado la instalación de la trata de personas como un discurso hegemónico ajeno a las dinámicas de los países sudamericanos. Por su parte, Denise Jardim $(2013,2017)$ revela en sendos análisis cómo operan las tecnologías de control sobre la vida de los migrantes. Este artículo sigue la línea de estas investigaciones y lo hace tomando como escenario para la reflexión algunas escenas de mi trabajo de campo en Brasil relacionadas con la celebración de la Primera Conferencia Nacional de Migraciones y Refugio - Comigrar.

La convocatoria para este dossier pedía a los participantes reflexionar acerca de la labor antropológica en relación con procesos migratorios en contextos en los que esta labor científica precisa ser defendida y, por ello, (re)pensada. El llamamiento señalaba una preferencia por artículos que reflexionaran acerca de los límites y dificultades para hacer etnografías sobre y con inmigrantes a partir de experiencias diversas y/o multilocales de investigación, que, entre otras cuestiones, visibilizan sujetos, actores y alianzas ya conocidos así como novedosos o inesperados. La lista de temas era extensa: herramientas teórico-metodológicas referidas a procesos migratorios, incidencia en agendas estatales, interpelación de poblaciones nativas en momentos cruciales de la vida de las personas migrantes, demandas de las personas migrantes e interseccionalidades, entre otros.

Partiendo de estas preguntas, este artículo analiza algunas formas del quehacer antropológico en medio de prácticas institucionales "que reciben extranjeros utilizando tecnologías de control globalizadas favorecedoras a primera vista de la circulación internacional" (Jardim, 2017, p. 24). Entiendo que el análisis del fenómeno migratorio -y uno de sus desafíos-implica pensar cómo operan las tecnologías de control que inciden sobre la experiencia migratoria. Por eso, retomo escenas de mi trabajo de campo junto a una red de actores gubernamentales y no gubernamentales en la lucha por la creación de políticas públicas específicas para migrantes y refugiados entre los años 2014 y 2016. Durante este tiempo acompañé una serie de eventos (reuniones, conferencias, audiencias públicas, mesas redondas y festivales) en las ciudades de Porto Alegre y San Pablo cuyo objetivo era la visibilización de la cuestión migratoria como un problema contemporáneo. En aquel entonces entendí esos eventos como espacios privilegiados de observación de los embates, tensiones y disputas tanto en la producción de una "población inmigrante" como en el proceso más amplio de construcción de la inmigración como un "dato, como un campo de intervención y como el objetivo de tecnologías de gobierno" (Franzé, 2013, p. 13). Es decir, reflexioné sobre las relaciones de saber-poder que producen la inmigración, y sobre el sujeto inmigrante como un tipo particular de población 
susceptible de intervención mediante una compleja trama de actores, tecnologías, saberes y relaciones.

Entretanto, y reconociendo las tensiones y luchas simbólicas que atraviesan las relaciones en los espacios donde investigué, reconozco que el "Estado" es una categoría política empleada por mis interlocutores, tanto por aquellos que se perciben como parte de él y quieren mostrar su "compromiso" con la cuestión migratoria como por aquellos que se piensan por "fuera". A pesar de las acusaciones hechas al "Estado", se continúan depositando en él las esperanzas y reivindicaciones en relación con la cuestión migratoria.

En la obra The Anthropology of the State. A Reader (2006), Sharma y Gupta reflexionan sobre la construcción de fronteras entre el "Estado" y la "sociedad civil" tanto en las prácticas cotidianas de las agencias estatales como en las representaciones que se elaboran en relación con el Estado. Para estos autores, el estudio de las rutinas, reglas y procedimientos agenciados por las burocracias estatales permiten entender los mecanismos por los cuales el Estado se hace presente en la vida cotidiana de las personas. De esta manera, la interacción directa de los individuos con los burócratas moldea los significados y las percepciones de la población sobre el Estado (Sharma y Gupta, 2006, p. 11). En la actuación repetitiva de las burocracias se apoya la continuidad de las instituciones estatales, al reproducir las condiciones que posibilitan pensar el Estado como una entidad coherente y homogénea situada encima de otras instituciones sociales. La continuidad reproduce la materialidad y las representaciones del Estado y es también por medio de las representaciones y discursos que se materializa la construcción de la estatalidad.

No obstante, los antropólogos y antropólogas sabemos que el poder del Estado -lo dejó claro Michel Trouillot (2001)- no tiene una única fijación institucional y por eso es necesario observar sus efectos fuera de las instituciones y agencias gubernamentales. Siguiendo esta premisa antropológica, acompañé el flujo de los encuentros de la red de mediadores de Porto Alegre y llegué a participar de la Primera Conferencia Nacional de Migraciones y Refugio en 2014. En lo que resta del artículo me centraré en algunas escenas de esta conferencia introduciendo primero la forma y metodología de la propia Comigrar como un modo de revelar no solo cómo operan las tecnologías de gobierno, sino también de qué manera los antropólogos/as nos hemos visto implicados en ellas en los últimos tiempos. En segundo lugar, presentaré la intervención de un refugiado congolés durante la Comigrar, porque su posicionamiento evidencia el enfrentamiento visible entre dos modos de hacer y pensar políticas migratorias: el que encarna la Conferencia Nacional y aquel otro que encarnan los migrantes y refugiados que viven en el centro de la ciudad de San Pablo. Dos modos de lucha que presentan tensiones y desafíos distintos en el quehacer antropológico.

\section{La discusión}

El eco de la convocatoria a una primera conferencia de migraciones y refugio generó cientos de encuentros a nivel regional, estadual y municipal que llegaron incluso a reunir a los brasileños residentes en el exterior. Así fue que más de cinco mil personas de todo el país se involucraron en la confección de propuestas para la Comigrar bajo una estricta metodología que supuso 202 conferencias regionales y más de 2800 propuestas elaboradas por 5300 participantes. Para ayudar en la organización de este encuentro se creó un 
portal virtual llamado "Plataforma Comigrar" coordinado por el Ministerio de Justicia en colaboración con el Ministerio de Trabajo y Empleo y el Ministerio de Relaciones Exteriores. La metodología basada en conferencias y la infraestructura digital fueron la base del encuentro. Por medio de ella se dieron a conocer el objetivo y el procedimiento por medio de la cual se celebraría la conferencia nacional.

De acuerdo con la plataforma online, el proceso de implementación de la Comigrar preveía la realización de eventos participativos movilizadores de actores locales vinculados con la temática migratoria. Esos eventos funcionarían como conferencias preparatorias de la etapa nacional y fueron presentados como oportunidades para promover la reflexión y el fortalecimiento institucional de colaboradores gubernamentales y no gubernamentales, así como también de migrantes, refugiados y representantes de la sociedad civil en un diálogo alrededor de temas relacionados con las migraciones y el refugio.

Para construir las propuestas a ser discutidas en la etapa nacional fueron creados un manual metodológico y un texto base. Este último presentaba los cinco ejes temáticos alrededor de los cuales se deberían agrupar las propuestas de las conferencias locales, municipales, estaduales, libres y virtuales, que eran: 1. Igualdad en el tratamiento y acceso a servicios y derechos; 2 . Inserción social, económica y productiva; 3 . Ciudadanía cultural y reconocimiento de la diversidad; 4 . Abordaje de violaciones de derechos y medios de prevención y protección; y 5. Participación social y ciudadana, transparencia y datos.

Todas las conferencias preparatorias tenían hasta cinco días para entregar un formulario base con el relato del evento, que además debía incluir las listas correspondientes a los delegados gubernamentales; de los delegados de la sociedad civil; de las propuestas con el número de votos que recibieron y de asistentes con la firma de los participantes. En el caso de las conferencias libres, no se pedía la elección de delegados gubernamentales, y en el caso de las conferencias virtuales no era necesario aportar la lista de los delegados gubernamentales ni la de los delegados de la sociedad civil. Las ideas surgidas de los eventos preparatorios fueron sistematizadas en un cuaderno de propuestas e identificadas con un código que permitía reconocer tanto su origen como aclarar sus contribuciones para la proposición final.

No obstante, mientras se estaban organizando las conferencias regionales, se comunicó desde el Ministerio de Justicia que se celebraría una "Feria Nacional de Prácticas de Lucha contra la Trata de Personas y Experiencias de Políticas Migratorias y Refugio". El plan de instalar una feria de este tipo durante el segundo día de la Comigrar no causó mayor sospecha ni malestar entre los miembros de la red de mediadores, sin embargo, no fue muy bien recibido por la Asociación Brasileña de Antropología (ABA). Por su parte, el Ministerio de Justicia explicó que la feria consistiría en "un espacio de divulgación, documentación y celebración de programas, proyectos y acciones promotoras y/o innovadoras en las áreas de combate a la trata de personas, políticas migratorias y refugio". Se aclaró también que el objetivo del evento era "estimular el intercambio de experiencias y ampliar el potencial de réplica e intercambio entre los diferentes actores que trabajan con las temáticas implicadas". Al finalizar la conferencia, la comisión evaluadora escogería tres de las prácticas presentadas y serían distinguidas con el premio Simone Borges Felipe.

La Asociación Brasileña de Antropología, junto con su Comité de Migraciones y Refugio, manifestó -mediante el documento oficio $N^{\circ}$ 018-2014-ABA-PRES- su 
sorpresa por lo que consideró una "indebida inserción" en el marco de la Comigrar. En la petición -dirigida al Ministerio de Justicia y elaborada con el foco puesto en la temática de la trata de personas- la ABA señalaba que la realización de la feria sería una contradicción entre el proyecto democrático participativo de la Comigrar -fundamentado en consultas previas y con foco en los derechos humanos- y su inconveniente relación con una pauta antitrata de personas generada por agencias multilaterales y utilizadas sobre todo por gobiernos del hemisferio norte como "instrumentos de contención de la movilidad humana, del libre ejercicio de la prostitución y en última instancia, de criminalización de la inmigración". El Ministerio de Justicia respondió con un documento, en el que diferenciaba las políticas migratorias del Estado brasileño de las llevadas a cabo por los "países del norte", estas últimas sí vinculadas a la restricción de la movilidad humana:

La Feria Nacional de Prácticas de Lucha contra la Trata de Personas y Experiencias de Políticas Migratorias y Refugio nace de la preocupación y compromiso gubernamental tanto en la lucha contra la trata de personas cuanto a la profundización de la sensibilidad del Estado Brasileño para el tratamiento de graves violaciones de derechos recurrentes en poblaciones migrantes, como uno de los ejes estructurales para el desarrollo de políticas y planes integrales de migraciones y refugio. La realización durante la Comigrar tiene por objetivo sumar las experiencias nacionales de protección y promoción de los derechos de los migrantes, refugiados y potenciales y efectivas víctimas de la trata de personas, así como avanzar en la transversalidad de la agenda migratoria en el sentido opuesto al control y vigilancia policial, reforzando los lazos profundos con el desarrollo de más y mejores condiciones de inclusión social plena y autónoma de la persona migrante. (Oficio № 175-2014-SNJ-MJ)

No hubo acuerdo entre estas dos posturas y finalmente la feria fue instalada en el espacio de tránsito de la conferencia. Contó con la exposición de quince prácticas, acciones, programas o proyectos identificados como "prometedores o innovadores" en las áreas de lucha contra la trata de personas, políticas migratorias y refugio. Durante la inauguración fueron pronunciados discursos en los que se enaltecían los derechos humanos, e incluso se destacaba el trato humanizado que la policía nacional daba a los inmigrantes.

Las contradicciones y ambigüedades características de un discurso hegemónico anti - trata, que oscila entre la defensa de los derechos humanos de las supuestas víctimas y la criminalización de prácticas respecto de actores sociales son, de un tiempo a esta parte, objeto de denuncia de diversas investigaciones antropológicas. El trabajo de Marcia Sprandel y Guillermo Mansur Dias (2010) sobre las políticas migratorias y la trata de personas es un claro ejemplo. En la misma línea, en un estudio que analiza aspectos de los regímenes discursivos y legales predominantes en España y Brasil sobre trata de personas, Adriana Piscitelli y Laura Lowenkron (2015) revelan que, aunque el Protocolo de Palermo esté destinado a combatir y prevenir la trata de personas y al mismo tiempo proteger los derechos fundamentales de las víctimas, en realidad forma parte de un conjunto de instrumentos orientados a la represión del crimen internacional, entre los cuales se encuentra también el protocolo relativo al combate contra el tráfico ilícito de migrantes (Piscitelli y Lowenkron, 2015).

El carácter securitario del actual debate migratorio relacionado con la búsqueda de nuevas estrategias de control por medio de políticas anti-trata de personas también es apuntado por Magliano y Clavijo (2013) en su trabajo sobre el papel de la Organización Internacional para las Migraciones (OIM). Las autoras destacan que, aunque sea posible reconocer un esfuerzo por desvincular las 
respuestas locales respecto de la migración de las acciones globales contra la delincuencia transnacional organizada, la concepción de la trata de personas como una forma abusiva de migración acaba por promover ese tipo de vinculación (Magliano y Clavijo, 2013).

Ciertamente, la controversia en torno a la realización de esta feria nos habla acerca de cómo pueden unirse, bajo retóricas amparadas en derechos humanos, cuestiones divergentes como las migraciones y la criminalidad. Nos habla también de prácticas discursivas internacionales y de su aplicación a nivel local. Al igual que en otros países de la región, la lucha contra la trata de personas ya contaba en Brasi ${ }^{1}$ con sus propios foros de debates y acciones.14 Además, en mi propio trabajo de investigación, esta disputa implicó también una enseñanza sobre el cómo del quehacer antropológico. Al transformar en dato lo dicho -tanto por el Ministerio de Justicia como por la Asociación Brasileña de Antropología- supuse estar mostrando mi propia inclinación por creer que la tarea ardua a la que nos enfrentamos como antropólogos/as es la de detectar, analizar y revelar las transformaciones conceptuales y políticas que luego tendrán efecto sobre la vida de las personas. En términos metodológicos, esto se transformó -sobre todo, en una primera fase del trabajo de campo- en un seguimiento privilegiado de lo que se decía, enunciaba o explicaba en los eventos que acompañé, en lugar de lo que se hacía en rutinas a las cuales yo no podía acceder. En este sentido, ciertamente descubrí, como apunta Julieta Quirós (2014), que el curso y los resultados de un campo etnográfico que permite al antropólogo participar de circuitos de intimidad social son muy distintos de aquellos implicados en un campo que solo habilita la participación en instancias "oficiales" hechas para decir (Quirós, 2014, p. 54).

$\mathrm{Al}$ realizar mi investigación en un momento histórico "singular" en Brasil (Jardim, 2013) en el que la llegada de inmigrantes se veía como un reflejo del crecimiento económico y la consolidación del país en el mercado internacional (Feldman-Bianco, 2016), se volvió necesario para mí estar atenta a las diferentes versiones sobre la creación de una política migratoria comúnmente entendida como un "modelo para el mundo". Poco a poco, por medio de los relatos de inmigrantes y otras personas a las que escuché, se revelaron otros aspectos de esta política. En varias ocasiones, y en contraste con la visión humanitaria presentada por agentes gubernamentales y no gubernamentales, las historias de las personas que escuché mostraban un desajuste entre la representación humanitaria y la situación experimentada diariamente por los inmigrantes. Para estas personas fueron, sobre todo, situaciones de precariedad, impotencia y falta de respeto las que caracterizaron su inserción en la sociedad brasileña. Por eso, más adelante, prioricé lo dicho y lo hecho por ellas. De esta manera, el curso del trabajo de campo me llevó a plantear nuevas preguntas para la investigación.

\section{La ruptura}

La Conferencia Nacional de Migraciones y Refugio comenzó con las palabras del entonces secretario de Justicia, Paulo Abrão. En su discurso de bienvenida remarcó que ese era el primer encuentro formal entre los migrantes de todo Brasil y las personas dedicadas a las migraciones y el refugio con el objetivo de debatir el futuro, planificar y construir proyectos conjuntamente. Además, resaltó que era la primera vez que las políticas nacionales de migraciones y refugio estaban siendo construidas con participación popular. Durante los aproximadamente quince minutos que duró su discurso, Abrão se refirió a la relación entre la Comigrar y los importantes cambios en el escenario brasileño
1. Brasil ratificó el Protocolo de Palermo de 2004, incluido en la Convención de las Naciones Unidas contra el Crimen Organizado Trasnacional, y desde entonces éste orienta tanto la Política Nacional de Lucha contra la Trata de Personas como los debates públicos sobre el tema. Brasil aprobó en 2006 una Política Nacional de Lucha contra la Trata de Personas (Decreto $N^{\circ} 5.948$ del 26 de octubre de 2006), y a continuación, en 2008, se lanzó el Primer Plan Nacional de Lucha contra la Trata de Personas (PNETP). Este tuvo continuación en 2013 con el Segundo Plan de Lucha contra la Trata de Personas (II PNETP). 
de los últimos tres años. Dejó claro que la elección de la cuestión migratoria era una prioridad para el gobierno, al destacar la formulación de una política humanitaria y al acentuar la importancia del papel de la sociedad civil.

Como parte de lo que fuera presentado como un intento de adopción de un nuevo posicionamiento en la cuestión migratoria se encontraba la creación de una comisión de especialistas para colaborar en la elaboración de una nueva ley de migraciones. Dicha comisión -organizada por el Ministerio de Justicia durante el año 2012- elaboró un anteproyecto de ley de migraciones que pasó por la evaluación de la sociedad civil durante la Comigrar y fue encaminado a la Presidencia de la República, y que fue sometido a discusión y aprobación del Congreso Nacional. No obstante, este era solo uno de los posicionamientos defendidos desde el Gobierno nacional. Existían, al menos, tres propuestas más.

Las tensiones y los debates sobre los lineamientos de la ley de migraciones quedaron patentes durante los grupos de trabajo organizados el segundo día de la conferencia. El objetivo de los grupos era profundizar en los planteamientos de las etapas anteriores y para ello se contaba con un dossier que había sistematizado en "recomendaciones estratégicas" las más de dos mil propuestas recibidas durante las conferencias preparatorias. Ninguna de ellas podría ser excluida ni total ni parcialmente, debiendo los participantes de la etapa nacional profundizar y complementar los textos. Para ello se organizaron seis "nubes temáticas", en las que se incluyeron los siguientes temas: igualdad de derechos y marco legal nacional e internacional; servicios y capacitación de agentes públicos y sociedad civil; servicios públicos, trabajo, salud y asistencia social; violación de derechos; brasileños en el exterior.

Por mi interés en conocer los debates relacionados con el marco legal, participé en la nube temática número uno. De acuerdo con la metodología previamente estipulada, se dejó claro que las propuestas no podían ser aprobadas o rechazadas, pero que todos los comentarios quedarían registrados.

Los comentarios y propuestas sugeridos durante la Comigrar fueron interesantes para percibir ciertos conflictos y tensiones relacionados con el cambio de la ley y discusiones más amplias sobre políticas migratorias. Sin embargo, este tipo de discusión no es la única que interesa a migrantes y refugiados. Una vez acabado el trabajo en grupo, pude oír las quejas y reclamos de un refugiado congolés sobre la actuación de organizaciones no gubernamentales (ONG) y del propio gobierno en cuanto a la acogida y atención de personas en situación de movilidad. Lo que esta persona nos decía era que las circunstancias por las que atravesaban migrantes y refugiados -incluyendo el hecho de vivir en ocupaciones del centro de la ciudad-no se debían solo a la inexistencia de políticas públicas para migrantes y refugiados sino que eran el resultado de la actuación conjunta de ONG y Gobierno. Esta impugnación desde su experiencia mostraba los límites de las acciones de acogida y políticas públicas. Lo que resalta de esta intervención es que cuestiones como acogimiento, representación de los migrantes, políticas públicas y vivienda podían y debían ser tratados de otra manera. Fue así que lo que en la conferencia estaba siendo tratado como un "momento histórico en la construcción de políticas para migrantes" se vio interrumpido. Como apuntan Estalella y Corsín Jimenez (2013) en su análisis de asambleas en Madrid, "las interrupciones son tales porque suponen la ruptura del ritmo esperado en ese lugar" (Estalella y Corsín Jimenez, 2013, p. 80).

Cuando conocí a Pitchou Luambo, el refugiado al que escuché en la Comigrar, había pasado más de un año desde la conferencia nacional. Transcurría el año 
2016 y Pitchou lideraba, desde la "Ocupación Hotel Cambridge", en el centro de San Pablo, el Grupo de Refugiados e Inmigrantes Sin Techo (GRIST). Lejos de lo que esperaba, el primer encuentro con Pitchou se había iniciado de una manera bastante brusca. Él me dejó bien claro que no me daría ninguna entrevista, explicándome que consideraba que "nosotros" -los investigadores-, así como otros agentes gubernamentales y no gubernamentales, nos "aprovechábamos" de ellos al utilizar sus historias para nuestro propio "beneficio", y que los tratábamos apenas como "objetos de estudio". En ese momento entendí que el discurso que me había llamado la atención durante la Comigrar no se refería únicamente a las organizaciones de acogimiento a migrantes y a sectores del gobierno, sino que incluía a un amplio abanico de antropólogos/as interesados en conocer "su punto de vista". Para Pitchou, era importante que yo entendiera su reivindicación a "hablar por sí mismo", sin mediaciones, incluida la mía como "investigadora", posición que como antropóloga y migrante respeto y comparto. ¿Qué implicó esto en términos de trabajo de campo? Prestar más atención a todos los lenguajes no discursivos implicados en el hacer de este y de otros refugiados.

"Tratar de otra manera" cuestiones como acogimiento, representación de los migrantes, políticas públicas y vivienda requería de un trabajo arduo y constante: reunirse con migrantes y refugiados de distintas nacionalidades, organizar eventos, asistir a conferencias, responder las solicitudes de investigadores, periodistas y psicólogos, entre otras muchas actividades -no estrictamente relacionadas con el activismo- formaban parte de la rutina de este congolés.

Las formas mediante las cuales personas en distintas situaciones de movilidad internacional vienen contestando discursos y prácticas que los colocan como "víctimas absolutas" o como personas reconocidas apenas a partir de su vulnerabilidad, son objeto de reflexión de los antropólogos en los últimos años. Realizadas sobre todo en campos de refugiados en Europa, lo que esas investigaciones empíricas muestran son distintas formas de contestación y movilización política en contextos sumamente críticos. Gracias a estos trabajos, conocemos las experiencias extremas de refugiados que desinflan balsas, venden su documentación, se cosen los labios o se encadenan. También, las de aquellos que reivindican un tratamiento mejor a partir de su vulnerabilidad. A partir del análisis de una manifestación de mujeres refugiadas en Sierra Leona, Michel Agier (2006) nos recuerda que la vulnerabilidad puede ser un "estatuto negociable". Para el autor, en escenarios complejos, actuar y tomar la palabra significa renunciar a la vulnerabilidad como tratamiento de la víctima pura e introducir la política y, con ella, un poco de ciudadanía a esas vidas sin nombre (Agier, 2006). Podría decirse que, en esos contextos, las acciones de los refugiados son entendidas como encarnaciones de una vida política que resiste.

Por otra parte, Stella Schindel (2016) nos adelanta una dimensión crucial de la agencia en los campos de refugiados y hace resonar la propuesta de Agier en un sentido distinto. Para la autora, la agencia de los refugiados es paradojal, porque muchas veces apela a una disolución de la identidad y hasta una deshumanización:

No alcanza, sostienen, con quemar los papeles; es preciso devenir animal, y el devenir es esencial a la movilidad; también devenir mujer, niño, anciano, sólido, fluido, movimientos de respuesta al control de su deseo. Transforman su constitución física, sus cuerpos, voces, acentos, pelo, color, altura, género, edad, biografías. La desestabilización del vínculo entre el cuerpo y la identidad es parte de la astucia de la migración, que abre la puerta a nuevas subjetividades indómitas. (Schindel, 2016, p. 25) 
En el contexto sudamericano, todavía son pocos los trabajos centrados en las prácticas de resistencia de refugiados e inmigrantes en el escenario actual. Existen, sin embargo, trabajos como los de Gabriel Gatti (2016) que, retomando la pregunta de Gayatry Spivak Can the subaltern speak? (1988), cuestionan la separación entre la víctima y el ciudadano y nos muestran así otras caras de las víctimas. Conocemos así victimas que hablan, escriben, actúan, más allá del sufrimiento y el dolor. Otros trabajos, como el de Natalia Gavazzo (2016), exploran las prácticas artístico-culturales de hijos jóvenes de inmigrantes bolivianos y paraguayos en Argentina para mostrarnos cómo los inmigrantes resignifican constantemente las fronteras culturales e identitarias, para posicionarse frente a las desigualdades, llevando a cabo acciones específicas para generar cambios en un contexto de desigualdad.

La tarde del 19 de junio de 2016, un escenario había sido colocado en la calle Álvaro de Carvalho, justo debajo del viaducto Nueve de Julio, en pleno centro de San Pablo. Yannik Delas, un músico congolés, cantaba en distintas lenguas africanas: lingala, kimbundu, kicongo. Mientras tanto, Fátima, una mujer senegalesa, mostraba coloridos vestidos a potenciales compradores. Muy cerca del escenario, en el restaurante palestino "Al Janiah", se formaba una fila enorme para los shawarmas y para el fufú, dos comidas típicas de Siria y del Congo ofrecidas aquella tarde. Mientras Yannik cantaba, algunos activistas repartían un folleto con información acerca del surgimiento del Frente Independiente de Refugiados e Inmigrantes (FIRI). "El FIRI será la voz de los refugiados para que podamos hablar por nosotros mismos" podía leerse en uno de los párrafos.

"Basta de corrupción, basta de manipulación, basta de racismo, xenofobia basta! Imperialismo basta, injusticia basta, hipocresía basta!". Esto cantaba Yannick en su canción Biliwé, una expresión en creole que significa "abre tus ojos". Mientras tanto, Shambuyi, un artista plástico también congolés, realizaba la performance "No a la guerra del Congo". Shambuyi, descalzo y con el cuerpo cubierto por papeles y plásticos pintados como si fuera sangre, caminaba entre la multitud mostrando varios teléfonos celulares colgados de su cuerpo en una acción que denuncia la extracción de minerales de la República Democrática del Congo. Después de algunas horas, los representantes del FIRI subieron al escenario para oficializar el lanzamiento del grupo. Pitchou dijo lo siguiente:

Creamos este movimiento para poder mostrar que el refugiado puede hablar por sí mismo y ser protagonista de su propia historia. No queremos competir con las ONG que hacen un trabajo muy importante para las personas recién llegadas, pero queremos promover la participación efectiva de inmigrantes y refugiados. (Nota de campo, 19-06-2016)

\section{Los desafíos}

He comenzado al artículo sugiriendo dos modos de hacer y pensar políticas migratorias con tensiones y desafíos distintos para el quehacer antropológico. A partir de la provocación planteada para este dossier, he tomado la Primera Conferencia Nacional de Migraciones y Refugio como escenario para mostrar cómo operan las tecnologías de control y de qué manera los antropólogos/as nos vemos mientras lidiamos con ellas. 
Las ideas presentes en los planes y orientaciones dirigidas hacia personas en distintas situaciones de movilidad tienen como objetivo la protección y promoción de los derechos humanos de los migrantes. Sin embargo, como afirman Piscitelli y Lowenkron (2015), el tipo de enfoque vinculado a la pauta ant-trata de personas mantiene una estrecha relación con instrumentos orientados a la represión del crimen trasnacional organizado. Ese es el escenario en el que antropólogos/as llaman la atención desde hace un tiempo sobre del carácter securitario del debate migratorio actual, centrado en la búsqueda de nuevas estrategias de control migratorio por medio de políticas anti-trata. No obstante, si bien este tema es algo que preocupa a los antropólogos/as que participan de dicho debate, hay que recordar que para muchos actores de este campo no representa en absoluto un problema. He aquí la magnitud que este desafío representa. Si bien somos invitados a eventos y conferencias donde se tratan estos temas, continúo preguntándome: ¿cuáles son los alcances de nuestras proposiciones?

Experiencias como la instalación de una Feria Nacional de Prácticas de Lucha contra la Trata de Personas y Experiencias de Políticas Migratorias y Refugio durante la Primera Conferencia Nacional de Migraciones y Refugio son un llamado a repensar lo que Eduardo Domenech (2013) llama "políticas de control con rostro humanitario". En este sentido, mi propuesta no puede ser otra que la de continuar estando atentos a aquellas ideas y planes de acción que, bajo un discurso de derechos humanos, conservan la misma finalidad que las políticas abiertamente restrictivas, y que garantizan, como afirma Domenech, incluso más efectividad en el control de los flujos migratorios internacionales. La sugerencia, sin embargo, es (re)pensar conjuntamente los modos en que las categorías de derechos humanos -incluso aquellas con las que trabajamos desde la antropología- y seguridad se entrelazan y se refuerzan mutuamente. Como sabemos hace tiempo gracias a Claudia Fonseca y Andrea Cardarello (1999, p. 85), la creación de un frente discursivo -fruto de la negociación entre diversos grupos de intereses que trabajan en torno a un mismo tema-puede ser una "espada de doble filo". Por un lado, fundamental para impulsar el apoyo político de manera amplia y eficaz, pero por otro lado, propensa a reificar el grupo con el que trabajamos, al nutrir imágenes que compiten con la complejidad de la realidad.

Por otra parte, como estrategia que permite el reconocimiento a migrantes y refugiados, el tratamiento como "víctimas" no debería ser pensando únicamente en función de los casos observados por antropólogos/as en el contexto europeo. Lo que pude ver en San Pablo fue cómo un grupo de inmigrantes y refugiados llamados "sin techo" transformaban prácticas artísticas en herramientas para llevar adelante un proyecto colectivo orientado a la transformación de las imágenes negativas que pesan sobre ellos. Las personas que conocí luchaban por una participación política y ciudadana real, y en ese contexto, nos planteaban como desafío la construcción de categorías y representaciones más plurales y menos estereotipadas sobre ellos.

\section{Sobre la autora}

Doctora en Antropología Social (Universidad Federal do Rio Grande do Sul, 2017). Licenciada en Sociología (Universidad de la Laguna, 2008). Máster en Gobernanza y Derechos Humanos (Universidad Autónoma de Madrid, 2011) y Máster en Investigación Etnográfica, Teoría Antropológica y Relaciones Interculturales (Universidad Autónoma de Barcelona, 2010). 


\section{Financiamiento:}

Para la realización del trabajo de campo que sustenta este artículo conté con una beca de la Organización de Estados Americanos (OEA) y con el apoyo de la Coordenação de Aperfeiçoamento de Pessoal de Nível Superior (CAPES).

\section{Agradecimientos:}

Agradezco a la Organización de Estados Americanos (OEA) y a la Coordenação de Aperfeiçoamento de Pessoal de Nível Superior (CAPES) por la financiación para realizar el trabajo de campo en el que se basa este artículo. Agradezco a los profesores y estudiantes del Programa de Pós-graduação en Antropología Social de la Universidade Federal do Rio Grande do Sul (PPGAS). 


\section{Q Referencias bibliográficas}

"Agier, M. (2006). Refugiados diante da nova ordem mundial. Tempo Social: Revista de Sociologia da USP, 18(2), 197-215. Recuperado de http://www.revistas.usp.br/ts/article/ view/12521 http://www.scielo.br/pdf/ts/v18n2/a1ov18n2

»Domenech, E. (2013). Las migraciones son como el agua: Hacia la instauración de políticas de "control con rostro humano": La gobernabilidad migratoria en la Argentina. Polis. Revista Latinoamericana, 12(35), 119-142. Recuperado de https://journals.openedition. org/polis/9280

»Estalella, A. y Corsín Jiménez, A. (2013). Asambleas al aire: La arquitectura ambulatoria de una política en suspensión. Revista de Antropología Experimental, 13. Volumen monográfico: Etnografías de la indignación, 73-88.

»Feldman-Bianco, B. (2016). Memórias de luta: Brasileiros no Exterior (1993-2010). Remhu-Revista Interdisciplinar da Mobilidade Humana, 24(48), 45-61. Recuperado de http:// www.redalyc.org/pdf/4070/407048610004.pdf

"Fonseca, C. y Cardarello, A. (1999). Direitos dos mais e menos humanos. Horizontes antropológicos, 5(10), 83-121.

" Franzé, A. M. (2013). Perspectivas antropológicas y etnográficas de las políticas públicas. Revista de Antropología Social, 22, 9-23. Recuperado de https://revistas.ucm.es/index.php/RASO/article/view/43771

"Gatti, G. (2016). El misterioso encanto de las víctimas. Revista de Estudios Sociales, 56(1), 117-120. Recuperado de https://revistas.uniandes.edu.co/doi/full/10.7440/res56.2016.09

" Gavazzo, N. (2016). Música y danza como espacios de participación de los jóvenes hijos de migrantes bolivianos y paraguayos en buenos aires (argentina). Revista del Museo de Anropología, 9(1), 83-94.

» Jardim, D. (2013). Os Direitos Humanos dos imigrantes: Reconfigurações normativas dos debates sobre imigrações no Brasil contemporâneo. Densidades, 14, 67-85. Recuperado de http://denisejardim.wixsite.com/antropologa/articles

" Jardim, D. (2017). Imigrantes o refugiados? Tecnologias de controle e as fronteiras. Jundial: Paco Editorial.

» Magliano, M. J. y Clavijo, J. (2013). La OIM como trafficking solver para la región sudamericana: sentidos de las nuevas estrategias de control migratorio. En G. Kasarik (Org.), Migraciones internacionales: reflexiones y estudios sobre la movilidad territorial contemporánea (pp. 129-148). Buenos Aires: Fundación Ciccus.

" Mansur Dias, G. y Sprandel, M, (2011), Reflexões sobre políticas para migrações e tráfico de pessoas no Brasil. Remhu - Revista Interdisciplinar da Mobilidade Humana, 37, 59-77.

" Mitchell, T. (2006). Society, Economy and the State Effect. En: Sharma, A. y Gupta, A. (Eds.), The Anthropology of the State: a reader (pp. 169-186). Oxford: Blackwell Publishing.

»Piscitelli, A. (2008). Entre as "mafias" e a "ajuda": a construção de conhecimento sobre tráfico de pessoas. Cadernos Pagu. São Paulo, n. 31, 29-63.

》Piscitelli, A. y Lowenkron, L. (2015). Categorias em movimento: a gestão de vítimas do tráfico de pessoas na Espanha e no Brasil. Ciência e Cultura, 2(67), 35-39. 
»Quirós, J. (2014). Etnografiar mundos vívidos. Desafíos de trabajo de campo, escritura y enseñanza en antropología. Publicar en Antropología y Ciencias Sociales, 17, 47-65. Recuperado de http://hdl.handle.net/11336/50883

"Sharma, A.; Gupta, A (2006). Rethinking Theories of The State in the Age of Globalization. En: Sharma, A. y Gupta, A. (Eds.), The Anthropology of the State: a reader (pp. 1-41). Oxford: Blackwell Publishing.

» Schindel, E. (2016). Migrantes y refugiados en las fronteras de Europa. Cualificación por el sufrimiento, nuda vida y agencias paradójicas. Revista de Estudios Sociales, 59, 16-29.

"Spivak, G. (1988) “Can the Subaltern Speak?” Marxism and the Interpretation of Culture. Eds. Cary Nelson and Lawrence Grossberg. Urbana: U of Illinois.

»Sprandel, M. A. y Mansur Dias, G. (2010). A temática do tráfico de pessoas no contexto brasileiro. Remhu - Revista Interdisciplinar da Mobilidade Humana, 35, 155-170. 